\title{
Mammography and Pap test screening among low-income foreign-born Hispanic women in the USA
}

\author{
Mamografia e teste Papanicolau em mulheres \\ latinas de baixa renda nos Estados Unidos
}

Maria E. Fernandez 1

Guillermo Tortolero-Luna 2

Robert S. Gold 3

\footnotetext{
1 University of Texas Houston Health Science Center, School of Public Health, Center for Health Promotion Research and Devel opment. 1200 Herman Pressler, Room W-938, Houston, Texas 77030-9960,USA.

2 Department of Gynecologic Oncology University of Texas M.D. Anderson Cancer Center, 1515 Hol combe Blvd., Box 67 , Houston, Texas,77030,U SA. 3 Macro International Inc. 11785 Beltsville Drive Calverton, Maryland 20705-3119,USA.
}

\begin{abstract}
Little is known about the factors influencing screening amonglow-income Hispanic women particularly among recent immigrants. A sample of 148 low-income, low-literate, foreign-born Hispanic women resi ding in theWashington DC metropolitan area participated in the study. The mean age of the sample was 46.2 (SD $=11.5$ ), 84\% reported annual household incomes $\leq \$ 15,000$. All women were Spanish speakers and had low acculturation levels. Ninety six percent had reported having a Pap smear, but $24 \%$ were not in compliance with recommended screening (Pap test within the last 3 years). Among women 40 and older, 62\% had received a mammogram, but only $33 \%$ were compliant with age appropriate recommended mammography screening guidelines. Women in this study had more misconceptions about cancer than Hispanics in other studies. Multivariate logistic models for correlates of Pap test and mammography screening behavior indicate that factors such as fear of the screening test, embarrassment, and lack of knowledge influenced screening behavior. In conclusion, women in this study had lower rates of mammography screening than non-Hispanic women and l ower rates of compliance with recommended Mammography and Pap test screening guidel ines.

Key words Breast Neoplasms; Mammography; Cervix Neoplasms; Hispanic Americans
\end{abstract}

Resumo Este estudo determinou os fatores que influenciam a conduta de mulheres latinas de baixa renda nos EUA, em face do monitoramento pela mamografia (MM) e por meio do teste de Papanicolau (TP), em uma amostra de 148 mulheres latinas, residentes na região metropolitana deWashington DC. A idademédia na amostra foi de 46,2 anos (desvio padrão 11,5), e84\% relatavam renda familiar anual menor que quinze mil dólares. Todas as mulheres falavam espanhol e apresentavam níveis reduzi dos de acul turação; 96\% destas informavam ter real izado TP, mas 24\% não rel atavam adesão às normas recomendadas de rastreamento. Entre aquelas com quarenta anos ou mais, $62 \%$ haviam realizado $\mathrm{MM}$, mas somente $33 \%$ de acordo com as normas de rotina. A freqüência deconcei tos equivocados sobre o câncer neste grupo de mulheres foi maior quea observada para mulheres latinas em outros estudos. Model os logísticos multivariados para variáveis correl aci onadas à conduta no rastreamento pelo TP e M M indi cam que fatores como o medo do teste, vergonha e desconhecimento tiveram influência. Concluiu-se que as mulheres nesse estudo a presentaram menor freqüência derastreamento por $M M$ que mul heres não latinas, além de apresentarem também níveis mais reduzi dos de adesão às normas de rastreamento por TP e MM. Palavras-chave Neoplasias Mamárias; Mamografia; Neoplasias do Colo Uterino; HispanoAmericanos 
The Hispanic population is the fastest growing ethnic minority group in the United States comprising $\mathbf{1 1 . 5} \%$ of the population (U.S. Bureau of the Census, 1997). The Census Bureau estimates that by the year $2050 \mathrm{Hispanics}$ will account for more than $25 \%$ of the U.S. population. Of the 28 million persons of Hispanic origin in the United States in 1996, more than one third were foreign born. Among Hispanics 25 years and older, there were more foreign-born people than U.S.-born, 7.9 and 6.7 million persons, respectively. Over 1.5 million foreignborn Hispanics were from Central America, including over 650,000 from El Salvador alone (U.S. Bureau of the Census, 1997). Since foreign-born Hispanics differ from native-born Hispanics in a number of ways, it is important to examine the factors that influence protective health behavior among this special and large group of Hispanics in the U.S. The current study examined correlates of mammography and Pap test screening behavior among foreign-born Hispanic women.

Although Hispanic women have a lower overall incidence of breast cancer than nonHispanic white women, they are at greater risk for presenting with larger tumors with regional or distant metastases (Daly et al., 1985; Richardson et al., 1987). Additionally, the incidence of breast cancer among Hispanic women is increasing at a rate three times greater than that of Anglo-women (Saint-Germain \& Longman, 1993). Cervical cancer is the third most common cancer among Hispanic women, while it ranks sixth for non-Hispanic white women (Hiatt \& Pasick, 1995). Among Hispanic women, both incidence and the mortality rates from cervical cancer are twice as high as those of non-Hispanic women (Miller et al., 1996; Anderson \& May, 1995; Texas Cancer Council, 1994).

Debate continues about appropriate screening intervals, the efficacy of screening for certain age groups, and cost effectiveness of screening. Still, there is widespread agreement that screening for breast and cervical cancers when combined with appropriate follow-up, will result in reductions in mortality from these cancers (Shapiro et al., 1988; Hurley \& Kaldor, 1992; Tabar et al. 1992).

Although screening rates for breast and cervical cancer are increasing, under-utilization is still a major concern in the United States (Hernandez, 1992; Fulton, 1992). Mammography screening can reduce breast cancer mortal ity by approximately one third through early detection and prompt treatment. However, barriers still exist that discourage or prohibit women, particularly minority women, from being screened (Rimer et al., 1991). Both the 1992 National Health Interview Survey and the 1995 Mammography Attitudes and Usage Study show that the proportion of women following guidelines for screening was lower among older, low income, low educated, and uninsured women (Anderson \& May, 1995; Martin et al., 1996).

Hispanic women are less likely to practice cancer screening behaviors including mammography, clinical breast exam, breast self-exam and Pap smear than non-Hispanic women (Fulton, 1992; Chavez et al., 1986; Harlan et al., 1991; Ramirez et al., 1987; Vernon et al., 1992; Breen \& Kessler, 1994). Furthermore, undocumented Hispanic women are less likely to have had Pap tests or practice BSE than their legal counterparts (Chavez et al., 1986). Data from the 1987 National Health Interview Survey showed that more Hispanic women (19.7 percent) had never heard of a Pap smear than either Black women (5.1 percent) or White women (2.6 percent) (Harlan et al., 1991). Spanish-speaking women were less likely to have heard of Pap smears and to have been in compliance with screening recommendations than English-speaking women. When comparing Hispanic women's compliance rates by country of origin, "Other Hispanics" had significantly lower rates than Cuban, M exican, and Puerto Rican women. This is important because "Other Hispanics" identified women from Central and South America. Many researchers have examined the reasons why some groups of women are chronically underscreened. (Zapka et al., 1996; O'Malley et al., 1997; Freeman \& Wasfie, 1989). Availability of services and financing of the screening services are only the most obvious. Women's knowledge about cancer and cancer screening, her beliefs about cancer risk, fears about screening, fatalism, embarrassment and concern about pain or discomfort can also have an impact on screening behaviors (Rimer et al., 1989; Pearlman et al., 1996; Rimer et al., 1996; Frazier et al., 1996; Hedegaard et al., 1996; Harlan et al., 1991; Calle et al., 1993; Tortolero-Luna et al., 1995; PerezStable et al., 1992; Morgan \& Levin, 1995). Many women who are motivated to obtain screening are deterred by environmental factors such as lack of transportation, lack of recommendation from a health care provider, lack of health insurance, cost, language barriers, and lack of social ties (O'Malley et al., 1997; Taylor et al., 1995; Fox \& Stein, 1991).

This paper examines the correlates of prior breast and cervical cancer screening among low-income, foreign-born Hispanic recruited 
to participate in a health education intervention study. The intervention assessed the effectiveness of a multimedia intervention on breast and cervical cancer screening knowledge, attitudes, and behavioral intent. The results of the intervention study are presented elsewhere (Fernandez, 1995). The analyses for the current paper were conducted on data gathered during a baseline interview among participants.

\section{Methods}

\section{Study sample}

The sampling frame for the study included Hispanic women living in or around Washington DC. Individuals of Hispanic origin or descent were those who classify themselves in one or more of the specific Hispanic origin categories such as Puerto Rican, Mexican, Central or South American, or Cuban, as well as those who indicated that they are of other Spanish/ Hispanic origin (U.S. Bureau of the Census, 1997). Participants were recruited through posted and verbal announcements. Flyers were posted in and around clinics and neighboring areas. Clinic staff also verbally recruited participants. Announcements were also made in Adult English as a Second Language (ESL) classes at the Spanish Education and Development Center (SED Center). A convenience sample was drawn from those women who expressed interest in participating and who fit the eligibility criteria. In order to be eligible for the study, the participant had to be a Hispanic woman, age 30 or older, with no history of cancer. Women who expressed an interest and met the eligibility criteria were asked to participate in an interview. One hundred and forty eight women participated in the interview.

Data collection

Six bilingual Hispanic interviewers (of Mexican, Central or South American origin) were recruited and trained. The interviewers became familiar with the objectives of the study, the research protocol, and the data collection instruments. Responses were recorded on pre-coded interview forms. A data collection coordinator was present at each site to ensure that the data collectors were following the data collection protocol, to assist in form completion, and to review all data forms for completeness. The Data collection period lasted for 15 days over a period of three and a half weeks.
Dependant variables

Four dichotomous dependent variables were used in the investigation, two variables describing mammography-screening status and two describing Pap test screening status. Behavioral intent to obtain a mammogram and/ or Pap test within the following three months was assessed among women who were non-adherent to screening guidelines.

Mammography status variables

Two dichotomous dependent variables were used to characterize prior breast cancer screening behavior. The first was whether or not a woman had ever received a mammogram. The second was a measurement of compliance with American Cancer Society (ACS) breast cancer screening guidelines. A woman was considered to be in compliance if she was age 40-49 years and had had a mammogram within the past two years prior to the study, or if she was 50 years and older and had had a mammogram within the year prior to the study. Analyses of screening behaviors for breast cancer were restricted to women 40 years and older.

Pap test status variables

Analogous to the mammography screening variables, two dichotomous dependent variables were also used to characterize prior cervical cancer screening behavior. The first was whether or not a woman had ever received a Pap test. The second was a measurement of compliance with screening guidelines for cervical cancer. Women reporting having had a Pap smear within the past three years prior to the study were considered to be in compliance with guidelines.

Behavioral intent

Behavioral intention is a person's intention to perform a behavior or more specifically, "the persons subjective probability that he/(she) will perform the behavior in question" (Fishbein \& Ajzen, 1985:12). We used a dichotomous variable indicating a woman's intent to obtain a mammogram or Pap test. The responses to the original question about intent to obtain a mammogram within the next three months were on a 4 point Likert scale ranging from very unlikely to very likely. These responses were re-coded into a dichotomous variable. This variable was only relevant for women who were in non-compliance with recommended 
guidelines according to their reported prior screening behavior.

\section{Covariates}

a) Demographics characteristics and acculturation: participants age, level of education, marital status, employment status, ethnic origin, place of birth, and length of time in the United States were obtained.

Acculturation is defined as the process of change occurring as a result of contact between cultural groups (Keefe, 1980). To assess the level of acculturation, a short 5 item Likert scale developed and validated by Marin et al. (1987) was used. Marin and colleagues state that the five items could represent a valid and reliable short acculturation scale (Marin et al., 1987). These items include language of preference to speak at home, with friends, read/speak, language used as a child, and language you think in.

b) Knowledge: Several questions concerning basic breast and cervical cancer knowledge were asked. Knowledge of screening methods was assessed by asking women to name methods of breast cancer screening ("ways there are to check for breast cancer"). Possible responses were "mammogram/mammography, clinical breast examination, and breast self-examination". The knowledge score was determined according to the number of methods a woman could mention. The range of responses was from zero to three. Knowledge of cervical cancer screening (Pap test) was also assessed by asking women if there was any way to check for cervical cancer, and if so, what were they. Certain responses such as "la prueba del cancer" (test for cancer) and "citología" (citology) were also acceptable responses.

Knowledge of signs and symptoms for breast cancer was also assessed. The list of signs and symptoms included presence of lumps, changes in the skin or surface of breast, changes or differences in breast size, and presence of secretions, blood, inflammation, and pain. The question was open-ended asking women to list all the signs and symptoms of breast cancer that they knew. Participants were also asked about specific recommendations regarding the frequency with which a woman their age should have a mammogram, clinical breast examination (CBE), Pap test, and practice breast selfexamination (BSE). Women were asked "how often should a healthy woman your age have a mammogram?" Similar questions were asked about a Pap smear, CBE, and breast self-exam?"

Knowledge about breast and cervical cancer screening methods, importance of early de- tection, and risk factors for breast and cervical cancer employing a “true/ false/ don't know" response format were also used. Knowledge questions were adapted from those used in an interview questionnaire about cancer screening (Saint-Germain \& Longman, 1993).

c) Attitudes about cancer: Items measuring attitudes about cancer were adapted from those developed by Perez-Stable et al. (1992). The items in this scale were also deemed relevant for foreign-born Hispanic women in the Washington DC area based on findings from focus groups and in-depth interviews conducted during the planning of this study. The attitudes reflected by the items also emerged in these focus groups and in-depth interviews (Hernandez, 1992).

d) Predisposing factors and barriers: Predisposing factors are characteristics of a person or population that motivate behavior prior to the occurrence of the behavior (Green \& Kreuter, 1991). These include fear of detection, embarrassment, fear of specific procedures, and the health belief model variables including perceived susceptibility, perceived benefits, and perceived barriers. A number of questions were used to measure these heal th belief model variables. Two questions that address perceived susceptibility, were adapted from a scale developed by Reynolds (1987) and were modified slightly to measure perceived susceptibility to cervical cancer as well as to breast cancer (Reynolds, 1987). Two other items asked about benefits and barriers to mammography screening. The instrument also included questions that asked participants about their level of fear and embarrassment of each of the screening procedures (Pap test, mammography, CBE, and BSE). Response options ranged from 1 to 10 . A subset of these items was used to calculate a Mammography Barriers scale that included items concerning those factors found to influence mammography utilization (Fox \& Stein, 1991). Reliability analysis revealed acceptable internal consistency reliability (.61).

Perceived Barriers are defined as the potential negative aspects of a health action (such as pain, embarrassment, or inconvenience of an anticipated behavior) that would be undertaken for the purpose of preventing or detecting disease, maintaining health, and curing or lessening undesirable consequences of a diseased state (Rosenstock et al., 1990). Four questions concerning barriers to screening were asked to women reporting never having had a Pap test, mammogram, CBE, or practiced BSE. These questions differed from most other questions in the interview instrument in that they were 
open-ended. The participant was asked to identify reasons why she had not had a Pap test, mammogram, CBE, or practiced BSE. These barrier questions were adapted from an interview question naire about cancer screening developed for use with low-income Hispanic women (Saint-Germain \& Longman, 1993).

d) Self efficacy: Is defined as "the conviction that one can successfully execute the behavior required to produce the outcomes" (Bandura, 1977:79). In the current study, self-efficacy refers specifically to self-perceptions of capacity to perform BSE, to communicate effectively with the physician (or health care provider), and to find ways to obtain access to health care (Gonzalez \& Gonzalez, 1990). Self-efficacy was measured by 11 items that elicit self-perceptions of capacity to perform and teach BSE, to communicate effectively with the physician (or health care provider), and to find ways to get access to health care. The self-efficacy scale used in the current study is made up of closed-ended, Likert-type questions developed by Gonzalez \& Gonzalez (1990). The Self Efficacy Scale was internally consistent with a Cronbach Alpha of .79. Subscales also showed good internal consistency: the BSE, overcoming barriers, and communications subscales had Cronbach Alphas of $.68, .58$, and .78 respectively.

The scales for acculturation, attitudes about cancer, and self-efficacy used in the present study had been previously translated and used in Spanish as well as in English. The remaining instruments were professionally translated and back-translated according to techniques recommended by Brislin, Lonner and Thorndike (Brislin et al., 1973; Chapman \& Carter, 1979).

\section{Statistical analysis}

Descriptive statistics were computed for all dependent variables (prior screening behavior and intention to obtain a mammogram) and covariates (demographics, acculturation level, barriers, knowledge, attitudes, predisposing factors, and self-efficacy). Bivariate relationships between dependent variables and covariates were tested for independence using Pearson's chi-squared test or Fisher's exact test. Furthermore, the relationships between outcomes and covariates were analyzed by two age strata (30-49 years and 50 years and older). First, univariate logistic regression models were used to assess the association between covariates on screening practices. Only variables with a $p$ value of $\leq 0.25$ (Wald $\chi^{2}$ ) in the univariate analysis were considered for inclu- sion in the multivariate analysis. Then, multivariate logistic models were performed to assess the independent effect of the selected variables on screening behaviors. Analyses of screening behaviors for breast cancer were restricted to women 40 years and older, while analyses for screening behaviors for cervical cancer included all women.

\section{Results}

\section{Study population}

A sample of $148 \mathrm{Hispanic}$ women living in or around Washington DC were included in the analysis. All were foreign-born Hispanics. The majority of the subjects were Central American (61\%) with the second largest group being South American (27\%). Only $7 \%$ and $5 \%$ of the subjects were Mexican and Caribbean, respectively (Table 1). Participants' age ranged from 30 to 77 years (mean age 46 years, SD $=11.5$ ).

Table 1

Demographic charateristics of study population.

\begin{tabular}{|c|c|c|}
\hline Variable & $\mathrm{n}$ & percent \\
\hline \multicolumn{3}{|l|}{ Age (years) } \\
\hline $30-39$ & 56 & 38 \\
\hline $40-49$ & 42 & 29 \\
\hline $50+$ & 49 & 33 \\
\hline \multicolumn{3}{|l|}{ Education (years) } \\
\hline$<6$ & 40 & 28 \\
\hline $6-11$ & 53 & 37 \\
\hline $12+$ & 52 & 36 \\
\hline \multicolumn{3}{|l|}{ Place of origin } \\
\hline Central America & 88 & 60 \\
\hline South America & 41 & 28 \\
\hline Mexico & 10 & 7 \\
\hline Caribbean & 8 & 5 \\
\hline \multicolumn{3}{|l|}{ Marital status } \\
\hline Single & 35 & 24 \\
\hline Married & 67 & 47 \\
\hline Separated/divorced & 19 & 13 \\
\hline Widowed & 15 & 10 \\
\hline Other & 11 & 7 \\
\hline \multicolumn{3}{|l|}{ Income } \\
\hline$<\$ 15,000$ & 121 & 84 \\
\hline$\$ 15,000+$ & 23 & 16 \\
\hline \multicolumn{3}{|l|}{ Employment } \\
\hline Full/part-time employed & 78 & 53 \\
\hline Not employed & 69 & 47 \\
\hline
\end{tabular}


The majority of women had low education levels with a mean of 8 years (SD $=4.5$ ) of school completed. Forty seven percent had six or less years of schooling and $15 \%$ of the sample had less than three years of formal education. Some of the subjects admitted to not knowing how to read, others requested that the data collector sign their name for them on the consent form. Fifty three percent of the women were employed at the time of the study (24\% full-time and $29 \%$ part-time employment) and one third of the women (37\%) indicated that they were unemployed. Yearly household incomes of less than $\$ 15,000$ were reported by $84 \%$ of the women. Fifty three percent of women were married or living in married-like situation, $24 \%$ were single, and $10 \%$ were widowed.

The length of time living in the United States varied considerably and ranged from less than one year to 33 years (mean 9, SD = 6.9). One third of the sample (34\%) had lived in the United States for 5 years or less indicating the relatively high proportion of recent immigrants. Although approximately $40 \%$ of the sample had lived in the United States for 10 years or more, these women still had relatively low acculturation levels as indicated by the acculturation scale. Fifty nine percent had thelowest possible acculturation score of five points (out of 25 points). Sixty seven percent of the sample reported speaking only Spanish, 95\% spoke only Spanish at home, $90 \%$ said they only thought in Spanish, and 83\% communicated with friends only in Spanish.

\section{- Screening behavior and intent}

Ninety three percent of women $(n=138)$ reported having ever had a Pap smear. However, only $42 \%$ of women had had one in the year prior to the study and $71 \%$ had had one within the previous three years. Therefore, $24 \%$ of the sample were not in compliance with screening recommendation guidelines for cervical cancer. Seventy eight percent of women reported having had a clinical breast exam and $79 \%$ had practiced breast-self examination at least once in their life. Among women over 40,62\% reported having had a mammogram, but only $33 \%$ were in compliance with screening recommendations at the time of study for a woman of their age (mammogram every one to two years for women 40-49 years old and annually for women 50 years and over). No differences in screening behaviors were observed between younger (less than 50 years old) and older women (Friedman et al., 1995). Eighty four percent of women in non-compliance with screen- ing mammography recommendations $(n=56)$ said that they were planning to obtain a screening mammography within the next 3 months. Among the 35 women not in compliance with Pap test screening guidelines, $79 \%$ said that they intended to receive a Pap within the next three months.

\section{Attitudes and beliefs}

Nineteen percent of participants said they would feel uncomfortable touching or kissing someone with cancer, $20 \%$ believed that cancer was a contagi ous disease, $63 \%$ were afraid of the word cancer, and $77 \%$ believed that cancer is like getting a death sentence. However, only $7 \%$ thought there is little one can do to prevent getting cancer and $13 \%$ percent did not believe that cervical cancer could be caused by a sexually transmitted disease.

\section{- Knowledge}

Knowledge about methods for early detection of breast and cervical cancer and signs and symptoms of cancer was low. Sixteen percent of women were not able to mention any method of early detection of breast cancer and $49 \%$ mentioned only one method. Fifty nine percent mentioned mammography, 33\% clinical breast exam, and $51 \%$ a breast self-exam. Similarly, only $66 \%$ were able to mention the Pap smear as a method for early detection of cervical cancer.

Although $65 \%$ and $55 \%$ of women reported that "lumpsin thebreast" and "pain" were signs and symptoms of breast cancer, only a small proportion of women were able to mention any others signs and symptoms. Very few women said that changes in breast size (2\%), scaly skin (4\%), swollen breasts ( $8 \%$ ), and secretion ( $12 \%$ ) were signs and symptoms of breast cancer.

Knowledge about screening recommendation guidelines was low. Seventy nine percent knew that a woman should have a Pap smear every one to three years. Sixty seven percent said that a woman should have a clinical breast exam annually. But only $52 \%$ of women knew the recommendation for screening mammography for a woman her age and only $42 \%$ knew that breastself-examination should be practiced monthly.

Although there were some misconceptions about breast and cervical cancer screening methods, importance of early detection, and risk factors for breast and cervical cancer, most women scored high on these knowledge scale items. Eighty five percent of women agreed 
that "mammography can detect lumps," 97\% agreed that "early detection of breast cancer increases the li kelihood of curing breast cancer," 98\% agreed that "a mammography was important for early detection of breast cancer," 95\% agreed that the "recommendation for women 50 years and over is annual mammography," 69\% agreed there were "al ternative treatment method for breast cancer other than mastectomy," and $85 \%$ of women agreed that the "risk of breast cancer is higher among women with family history." In addition, $96 \%$ said it was true that the "Pap test was a test to detect cervical cancer," and $74 \%$ and $72 \%$ agreed that "some cancers are caused by sexually transmitted diseases," and "a high fat intake increases the risk of some types of cancer." Lower levels of knowledge were evident in other areas. For example, $60 \%$ of women incorrectly agreed that the "risk of breast cancer decreases with age," 79\% thought that "injuries increase the risk of cancer," and 32\% indicated that it was true that "a woman does not need a mammography unless there is a lump." Additionally 34\% incorrectly agreed that "there is no need of breast self-examination if mammography is negative" and only $45 \%$ of women agreed that "breast self examination should be performed monthly."

Predisposing factors and barriers

Approximately $22 \%$ of women said that they did not feel susceptible to breast or cervical cancer. Several barriers to screening were identified in this population. Embarrassment about the Pap smear test was expressed by $53 \%$ of women, whereas, one-third of the women said they would be embarrassed about mammography (36\%) and clinical breast exam (34\%). Only $13 \%$ of women, however, said they would be embarrassed about practicing a breast self-exam. A large proportion of women reported fear of detecting cancer (90\%). Whereas, about half of the women reported fear about the Pap smear test (56\%), mammography procedure (46\%), and clinical breast exam (44\%). In addition, $55 \%$ said they were afraid of mammography being painful and $48 \%$ expressed that the cost of mammography would be a barrier to obtain one.

The most common reasons expressed by women aged 40 years and over for never having had a mammogram ( $n=34)$ or a clinical breast exam ( $n=35$ ) were lack of signs and symptoms (10 and 11 women, respectively) and lack of a doctor's recommendation ( 6 and 4 women, respectively). Only two women mentioned embarrassment or cost of mammogra- phy, and two women said embarrassment for a clinical breast exam as a reason for never having obtained the tests. Whereas, half of the women who reported never having performed a breast self-exam ( $n=27$ ) expressed that the main reason was not knowing how to perform it $(n=13)$. Among the small number of women who reported never having had a Pap smear, ( $\mathrm{n}$ $=10$ ) three expressed that they "never thought about it/forgot" and two expressed "cost" as the reason for not having had the test.

\section{- Self-efficacy}

Self-efficacy to communicate effectively with health care providers and to overcome environmental barriers was high. However self-efficacy to perform and teach breast self-examination was lower. Over $80 \%$ percent of women responded that they were certain or somewhat certain that they could "ask questions to a provider" (89\%), "understand a health provider's explanation" (85\%), "understand the exam" (86\%), and "explain results to others" (86\%). Similarly, large proportions of women were confident or somewhat confident that they could "keep doctors' appointments" (88\%), "follow doctors' recommendations" (95\%), and "have somebody to take them to their appointments" (78\%). Fewer women, however, said they were confident or somewhat confident they could: perform a breast self-examination (57\%), detect a lump (53\%), or teach someone el se the breast self-exam (58\%).

\section{- Univariate analysis}

There were no statistically significant differences between Pap smear prior screening behaviors (ever having had the test and compliance with recommended guidelines) and age, education, employment status, and family income. Women that expressed embarrassment for the test were less likely to have had a prior Pap smears than those who said they were not embarrassed ( $89 \%$ vs. $97 \%, p=0.07$ ). Women who reported being embarrassed about the Pap test were significantly less likely to have had one within the 3 years prior to the interview ( $64 \%$ vs. $83 \%, p=0.02$ ). Women who said they "would not want to know if the had incurable cancer" were less likely to have had a Pap smear (83\%) than women who said they "would like to know" (95\%) ( $p=0.05)$. These women were also less likely to have been in compliance with screening guidelines ( $65 \%$ vs. $78 \%, p=$ 0.19). Similarly, women with lower scores on the self-efficacy to overcome barriers sub-scale 
were less likely to have ever had a Pap smear than women with higher scores (83\% vs. 95\%, p $=0.06$ ). No significant differences in the proportion of women in compliance with cervical cancer screening recommendation were detected between women with low and high selfefficacy score. Similarly, no significant associations were observed between cervical screening behaviors and fear of detecting cancer or fear of the word cancer.

Only "fear of mammography" was statistically significantly associated with both having ever had a mammogram and with compliance with breast cancer screening guidelines. Women reporting "fear of the mammography" were less likely to have ever had a mammogram than women who said they were "not afraid of the test" $46 \%$ vs. $75 \%, p=.02)$ and were less likely to be in compliance with screening recommendations ( $16 \%$ vs. $47 \%, p=0.009$ ). Although not statistically significant, women who said they were "very fearful of detecting cancer" were less likely to have ever had a mammogram (58\% vs. $70 \%$ ). Older women (aged 50 years and over) were more likely to report ever having had a mammography than women aged $40-49$ years old ( $69 \%$ vs. $52 \%, p=0.10)$. The proportion of women reporting having ever had a mammogram increased with increasing number of years she resi ded in the U.S. Among women with five of less years of residency in the U.S., 48\% reported having had a mammogram compared to $62 \%$ of those with 6-9 years and $69 \%$ of those with 10 or more years of residency ( $p=0.24)$. Women reporting that they were "embarrassed by thetest" were less likely to have ever had a mammogram than women reporting not being embarrassed by the test (46\% vs. $70 \%, p=0.13$ ) They were also less likely to be in compliance with screening guidelines ( $21 \%$ vs. $44 \%, p=0.07)$.

\section{- Multivariate analysis}

After considering all the other variables in the model only self-efficacy to overcome barriers remained a statistically significant predictor of Pap smear screening (Table 2). Women with a low self-efficacy score were $90 \%$ less likely to have ever had a Pap smear $(\mathrm{OR}=0.09 ; 95 \% \mathrm{Cl}$ 0.01-0.63). Although not statistically significant, women with less than 6 years of education and women who said they were afraid of the test were $77 \%$ and $68 \%$ less likely to have ever had a Pap smear respectively. Embarrassment about the Pap smear was an independent factor associated with a lower likelihood of having had a Pap smear within the three years prior to the study after consideration for age, education, years living in the U.S., and self-efficacy commun ication score (Table 3). Women reporting that they were very embarrassed by the Pap test were 68\% less likely to have had a test within the last three years (OR $=0.32 ; 95 \%$ $\mathrm{Cl}$ 0.13-0.80). Unlike the association observed between Pap test screening and self-efficacy for overcoming barriers, women with lower scores on the sub-scale assessing self-efficacy for communicating with providers were, surprisingly, 6 times more likely to report ever having had a Pap smear $(\mathrm{OR}=6.25 ; 95 \% \mathrm{Cl}$ 1.18-32.97).

Among women aged 40 years and older the only factor independently associated with ever having had a mammogram was knowledge score (Table 4). Women with intermediate and low knowledge scores were 86\% (OR $=0.14$; $95 \% \mathrm{Cl} 0.03-0.75)$ and $88 \%(\mathrm{OR}=0.12 ; 95 \% \mathrm{Cl}$ 0.02-0.76) less likely to have ever had a mammography than women with high knowledge scores. The results also suggest that "fear of the test" may be associated with a lower likelihood of having ever had a mammography. Women reporting to be somewhat fearful of the test were $83 \%$ less likely to have ever had a mammography $(\mathrm{OR}=0.17 ; 95 \% \mathrm{Cl} 0.03-0.91)$ and those reporting to be very fearful of the test were $61 \%$ less likely to have ever had the test (OR $=0.39 ; 95 \% \mathrm{Cl} 0.12-1.29$ ). No other factors were significantly associated with this behavior although, women who said they were very em-

Table 2

Multivariate logistic regression for ever having had a pap smear among women 30 years and older.

\begin{tabular}{llr}
\hline Variable & OR & $95 \% \mathrm{Cl}$ \\
\hline $\begin{array}{l}\text { Age (years) } \\
\quad<50\end{array}$ & & \\
$\quad 50+$ & 1.0 & \\
Education (years) & 0.58 & $0.11-3.18$ \\
$\quad$ 12+ & & \\
$\quad 6-11$ & 1.0 & \\
$\quad<6$ & 4.10 & $0.35-48.39$ \\
Fear of pap smear & 0.23 & $0.04-1.46$ \\
$\quad$ No fear & & \\
$\quad$ Some fear & 1.0 & \\
Fear & 0.96 & $0.07-12.38$ \\
Self-efficacy to & 0.32 & $0.06-1.79$ \\
overcome barriers & & \\
High & & \\
Low & 1.0 & $0.01-0.63$ \\
& 0.09 &
\end{tabular}


barrassed about mammography, who reportedly fearful of the procedure, and who those considered cost a barrier for obtaining a test, were less likely to report ever having had a mammogram.

Fear of the test was found to be associated with compliance with recommended mammography guidelines in a similar way as the association observed for having ever had a mammogram (Table 5). Women reporting to be somewhat fearful of the test were $91 \%$ less likely to be in compliance with recommended guidelines (OR $=0.09 ; 95 \% \mathrm{Cl} 0.01-0.92$ ) and those who said they were very fearful of the test were $61 \%$ less likely to have ever the test (OR $=$ $0.29 ; 95 \% \mathrm{Cl} 0.29-1.19)$. Although not statistically significant, older women, women with lower levels of education and knowledge score, and women who expressed embarrassment or fear of mammography were less likely to have been in compliance with screening recommendations.

Table 3

Multivariate logistic regression for compliance with pap smear guidelines (3 years) among wo men 30 years and older.

\begin{tabular}{|c|c|c|}
\hline Variable & OR & $95 \% \mathrm{Cl}$ \\
\hline \multicolumn{3}{|l|}{ Age (years) } \\
\hline$<50$ & 1.0 & \\
\hline $50+$ & 0.96 & $0.38-2.39$ \\
\hline \multicolumn{3}{|l|}{ Education (years) } \\
\hline $12+$ & 1.0 & \\
\hline $6-11$ & 1.39 & $0.49-4.00$ \\
\hline$<6$ & 0.77 & $0.28-2.14$ \\
\hline \multicolumn{3}{|l|}{ Years leaving in the U.S. } \\
\hline $10+$ & 1.0 & \\
\hline $5-9$ & 2.08 & $0.71-6.07$ \\
\hline$<5$ & 1.16 & $0.38-7.28$ \\
\hline \multicolumn{3}{|l|}{$\begin{array}{l}\text { Embarrassed by } \\
\text { pap smear }\end{array}$} \\
\hline Not embarrassed & 1.0 & \\
\hline Somewhat embarrassed & 1.66 & $0.38-7.28$ \\
\hline Very embarrassed & 0.32 & $0.13-0.80$ \\
\hline \multicolumn{3}{|l|}{$\begin{array}{l}\text { Self-efficacy } \\
\text { communication score }\end{array}$} \\
\hline High & 1.0 & \\
\hline Low & 6.25 & $1.18-32.97$ \\
\hline \multicolumn{3}{|l|}{$\begin{array}{l}\text { If diagnosed with cancer } \\
\text { would like to know }\end{array}$} \\
\hline Yes & 1.0 & \\
\hline No & 0.40 & $0.13-1.28$ \\
\hline
\end{tabular}

\section{Discussion}

The results of this study indicate that the factors influencing breast and cervical cancer screening among low income foreign-born Hispanic women are similar to those associated with screening behavior among other groups of Hispanic women. However, some differences were identified when findings were compared with previous studies among various groups of Hispanic women. Sixty two percent of women had had a least one mammogram in their lifetime and only $33 \%$ were in compliance with screening recommendations. These results are similar to those observed by Tortolero-Luna et al. (1995) in Corpus Christi, Texas and by Kaplan et al. (1996) in Arizona, San Diego, Colorado and California, but higher than those reported by the $\mathrm{NCl}$ Cancer Screening Consortium (1995) and Kaplan et al. (1996) in Texas.

A large percentage of women reported having had a Pap test at least once in their lives (93\%), having had one within the last three

Table 4

Multivariate logistic regression for ever having had a mammography among women 40 years and older.

\begin{tabular}{|c|c|c|}
\hline Variable & OR & $95 \% \mathrm{Cl}$ \\
\hline \multicolumn{3}{|l|}{ Age (years) } \\
\hline $40-49$ & 1.0 & \\
\hline $50+$ & 2.04 & $0.72-5.79$ \\
\hline \multicolumn{3}{|l|}{ Knowledge score } \\
\hline High & 1.0 & \\
\hline Intermediate & 0.14 & $0.03-0.75$ \\
\hline Low & 0.12 & $0.02-0.76$ \\
\hline \multicolumn{3}{|l|}{$\begin{array}{l}\text { Embarrassed by } \\
\text { mammography }\end{array}$} \\
\hline Not embarrassed & 1.0 & \\
\hline Somewhat embarrassed & 1.03 & $0.24-4.36$ \\
\hline Very embarrassed & 0.45 & $0.14-1.51$ \\
\hline \multicolumn{3}{|l|}{ Fear of mammography } \\
\hline No fear & 1.0 & \\
\hline Some fear & 0.17 & $0.03-0.91$ \\
\hline Fear & 0.39 & $0.12-1.29$ \\
\hline \multicolumn{3}{|l|}{$\begin{array}{l}\text { Cost is barrier for } \\
\text { mammography }\end{array}$} \\
\hline Unlikely & 1.0 & \\
\hline Somewhat unlikely & 1.03 & $0.24-4.36$ \\
\hline Very likely & 0.45 & $0.14-1.51$ \\
\hline \multicolumn{3}{|l|}{ Fear of word cancer } \\
\hline No & 1.0 & \\
\hline Yes & 2.81 & $0.94-8.41$ \\
\hline
\end{tabular}


Table 5

Multivariate logistic regression for compliance with mammo graphy guidelines among women 40 years and older.

\begin{tabular}{|c|c|c|}
\hline Variable & OR & $95 \% \mathrm{Cl}$ \\
\hline \multicolumn{3}{|l|}{ Age (years) } \\
\hline 40-49 & 1.0 & \\
\hline $50+$ & 0.7 & $0.22-2.04$ \\
\hline \multicolumn{3}{|l|}{ Education (years) } \\
\hline $12+$ & 1.0 & \\
\hline $6-11$ & 1.14 & $0.29-4.51$ \\
\hline$<6$ & 0.53 & $0.13-2.25$ \\
\hline \multicolumn{3}{|l|}{ Knowledge score } \\
\hline High & 1.0 & \\
\hline Intermediate & 0.82 & $0.20-3.28$ \\
\hline Low & 0.53 & $0.13-2.25$ \\
\hline \multicolumn{3}{|l|}{$\begin{array}{l}\text { Embarrassed by } \\
\text { mammography }\end{array}$} \\
\hline $\mathrm{N}$ ot embarrassed & 1.0 & \\
\hline Somewhat embarrassed & 0.57 & $0.11-3.02$ \\
\hline Very embarrassed & 0.72 & $0.18-2.93$ \\
\hline \multicolumn{3}{|l|}{ Fear of mammography } \\
\hline No fear & 1.0 & \\
\hline Some fear & 0.09 & $0.01-0.92$ \\
\hline Fear & 0.29 & $0.07-1.19$ \\
\hline \multicolumn{3}{|l|}{$\begin{array}{l}\text { Self-efficacy } \\
\text { communication score }\end{array}$} \\
\hline High & 1.0 & \\
\hline Low & 0.47 & $0.07-3.37$ \\
\hline \multicolumn{3}{|l|}{$\begin{array}{l}\text { Self-efficacy to } \\
\text { overcome barriers }\end{array}$} \\
\hline High & 1.0 & \\
\hline Low & 1.01 & $0.18-16.84$ \\
\hline
\end{tabular}

years $(71 \%)$, and having had one within the year prior to study (42\%). The high proportion of women reporting having ever had a Pap smear is similar to that reported among Hispanic women in Texas. Ninety five percent of women 35 years and older in Corpus Christi, Texas reported having ever had a Pap smear (Tortolero-Luna et al., 1995). Similarly, $82 \%$ of urban Hispanic women 40 years and older residing in Texas reported having had at least one Pap smear in their lifetime (The National Cancer I nstitute/ Cancer Screening Consortium for Underserved Women, 1995). The percent of women reporting having had a Pap smear within the last three years (71\%) was slightly lower than that reported by Perez-Stable et al. (1994) in California (88\%) but higher than in Texas Hispanics (57\%) (The National Cancer Insti- tute/ Cancer Screening Consortium for Underserved Women, 1995).

Interpretation and comparison of screening rates between studies needs to take into consideration recent upward trends in cervical and breast cancer screening (Ackermann et al., 1992). Three recent studies support this increasing trend, particularly among Hispanic women (Breen \& Kessler, 1994) (Kaplan et al., 1996) (Anderson \& May, 1995). Data from the 1987 and 1990 National Health Interview surveys indicate that the proportion of Hispanic women reporting screening mammograms within the last year increased from 13\% in 1987 to $31 \%$ in 1990 (Breen \& Kessler, 1994). Similarly, Kaplan et al. (1996) suggested an increasing trend in mammography screening among Hispanic women from approximately $20 \%$ in 1987 to approximately 60\% in 1993 (Kaplan et al., 1996). Anderson \& May (1995) also observed an increasing trend in cervical cancer screening rates among Hispanic women. These data suggests that the increase in screening rates over time may be partially attributable to public health education and other heal th promotion efforts to increase screening awareness and utilization.

Misconceptions about cancer and fatalistic attitudes toward diagnosis and treatment have been reported more frequently among Hispanic women than in non-Hispanics women (Perez-Stable et al., 1995; Napoles-Springer et al., 1996; Tortolero-Luna et al., 1995; Morgan \& Levin, 1995). Similarly, knowledge about cancer, signs and symptoms of cancer, early detection methods, and frequency of screening is lower among Hispanic women (Perez-Stable et al., 1995; Napoles-Springer et al., 1996; Tortolero-Luna et al., 1995; Morgan \& Levin, 1995). Compared with previous studies, a larger proportion of women in our study had misconceptions about cancer. For example, $79 \%$ in our study agreed that "injuries could increase the risk of cancer" compared with 58\% in the study by Morgan \& Levin (1995). Seventy seven percent of our sample agreed that cancer was a death sentence compared with $46 \%$ by PerezStable (1992), 54\% by Tortolero-Luna et al. (1995), and 56\% by Morgan \& Levin (1995).

We found that $20 \%$ of women believed that cancer is contagious, whereas only $9 \%$ of women in the study by Morgan \& Levin (1995) did. In addition, fear of the word "cancer" was reported by $63 \%$ of our sample and $71 \%$ in the study by Tortolero-Luna et al. (1995). Similarly, knowledge about cancer, signs and symptoms of cancer, early detection methods, and frequency of screening was low in our study as in 
other studies among Hispanic women (PerezStable et al., 1995; Napoles-Springer et al., 1996; Tortolero-Luna et al., 1995; Morgan \& Levin, 1995).

It is important to note that women performed much better in the "true/false" knowledge items than on the open-ended items that asked them to recall information (e.g. about screening or signs and symptoms of cancer). Hence the difference in percent correct between the $96 \%$ of women who agreed with the true/ false statement that a Pap test is to test for cervical cancer versus the $66 \%$ of women who were able to mention the Pap test when asked about "ways to detect cervical cancer." The true/ false items measure the lowest level of knowledge, (i.e. recognition) while the openended items more accurately assess understanding.

In previous studies, fear of finding cancer and fear of the screening procedure have both emerged as barriers to breast and cervical cancer screening (Bastani et al., 1994; Munn, 1993; Roetzheim et al., 1993). In the current study, fear of detection was also associated with screening behavior although the findings were not statistically significant. For example women reporting higher levels of fear of detecting cancer were less likel y to have ever had a mammogram. By contrast, women who reported higher levels of fear about the word cancer were more likely to have had a mammogram (OR $=2.81, \mathrm{Cl}$ 0.94-8.41) and to be compliant with recommended breast cancer screening guidelines (OR $=5.83, \mathrm{Cl} 1.52-22.36$ ). Why would fear of the word cancer be positively associated with mammography screening, but fear of detecting cancer be negatively associated with mammography? Perhaps these seemingly contradictory findings indicate that items inquiring about fear of the word "cancer" and fear of detecting cancer measure two distinct constructs. Fear of the word cancer denotes a general worry or anxiety about the disease whereas fear of detecting cancer may assess a very specific fear more closely related to the act of screening. Whereas fear of the word cancer may act as a motivating factor cueing women to act to protect their health, fear of detecting cancer may represent a negative belief closely related to the cultural theme of fatalismo (Chavez et al., 1997). Fatilismo may be a barrier in the sense that it may lead some Hispanics to assume that there is little that they can do to prevent cancer (Perez-Stable et al ., 1992). Furthermore, the belief that cancer is a death sentence among a large proportion of women in our study (77\%), may act as a significant deterrent to screening practices. Women may believe that if cancer always means death there is no point to screening, and they may prefer not to know they have cancer. The proportion of women reporting that they thought cancer was like a death sentence in this study was higher than among California Hispanics in a previous study (77\% vs. 46\%) (Perez-Stable et al., 1992).

Fear of the screening test was a significant barrier to breast and cervical cancer screening among women in the sample. Women reporting at least some fear of the procedure were between $60 \%$ and $80 \%$ less likely to have ever had a mammogram and $70 \%$ to $90 \%$ less likely to be in compliance with mammography screening guidelines. For Pap test, women reporting fear of the exam were almost $70 \%$ less likely to ever have received it. These findings suggest that although fear of cancer may not deter a woman from screening, fear of the screening procedure itself is a barrier that should be addressed among low income foreign born Hispanic women. It is unclear whether or not this fear is based on a fear of the unknown, a woman's own prior experience, or what other women have told them about the procedure.

Embarrassment was an important factor influencing Pap test utilization among the study population. Women who said they would be embarrassed about having a Pap test were significantly less likely to be in compliance with Pap test screening guidelines ( $\mathrm{OR}=.32, \mathrm{Cl} .13-$ .80). Similarly, women who said they would be "very embarrassed" about having a mammogram were about half as likely to have ever had one or to be in compliance with recommended mammography screening guidelines. Several studies concur with this finding and note that women who indicate embarrassment are less likely to have had a mammogram or a Pap test in the past year (Stein et al., 1992; Harlan et al., 1991; Richardson et al., 1992).

Many studies have indicated that cost is an important barrier to mammography utilization (Breen \& Kessler, 1994; Bastani et al., 1994; Vogel et al., 1993). This factor may be even more salient among low-income and Hispanic women (Hernandez, 1992). Although not statistically significant, women in the current study who reported that it would be "very likely" that the cost of a mammogram would keep them from getting one were less than half as likely to have ever had a mammogram. Cost did not emerge as an important barrier to mammography screening compliance however. This variable essentially measured a woman's perception of cost as a barrier regardless of whether or not cost truly limited access to 
screening services. There are many programs that provide low and no cost screening to women in need. Health fairs offering free mammography and Pap test screening are conducted every year in the community from which the sample was selected. It is likely that cost was a perceived barrier among women who had never had a mammogram but among those who had, (and were simply non-compliant with screening recommendations) cost was not as important issue because they knew how to obtain low cost mammograms.

Because there was little variability in acculturation levels among women in the sample, it did not provide much information as an explanatory variable in the multivariate models. The number of years in the United States was a variable considered in the multivariate models, but did not emerge as a factor influencing mammography or Pap test screening. Results indicated, however, that women living in the US for 5-9 years were twice as likely to be in compliance with recommended Pap test screening guidel ines as recent immigrants (less than 5 years) and women who had lived in the US for ten or more years. Recent immigrants may have lower screening rates than others for several reasons. Problems with an "undocumented" status make it difficult to obtain health care because they may be ineligible for federal programs. Recent immigrants have many other barriers including, language, competing priorities, and lack of knowledge about screening that may prevent them from obtain ing needed screenings. It is less clear why women who had lived in the US for ten years or more were less likely to be in compliance with recommended guidelines than women who had lived in the US for 5-9 years.

Knowledge about breast and cervical cancer and cancer screening significantly predicted mammography screening among women in the study. Women with low levels of knowledge were significantly less likely $(\mathrm{OR}=.12, \mathrm{Cl} 0.02$ $0.76)$ to have ever had a mammogram. Knowledge however was not important in predicting Pap test screening in this population. Although many studies have demonstrated that knowledge alone is not predictive of health behavior, certain types of knowledge are often prerequisites for behavior adoption or change to occur. For example, for a woman to practice breast cancer screening according to the appropriate age-specific recommendations, she needs to know what type of test she needs and what those recommendations are. Other, more general types of knowledge such as information about the anatomy of the breast or the biology of cancer would most likely be unrelated to mammography screening. The specific type of knowledge assessed in the current study dealt with types of breast and cervical cancer screening and screening recommendations, and awareness that breast and cervical cancer, if detected early can be cured. The misconceptions about cancer mentioned above demonstrate the lack of basic knowledge about cancer and early detection among many women in the sample. Because these misconceptions lead to other barriers such as fear, belief that cancer is incurable, and misconceptions about treatment, lack of knowledge may be an even more important factor influencing screening among very low literate women and those with low education levels.

Women who had low self-efficacy in overcoming barriers were significantly less likely to have ever had a Pap test. By contrast, a bel ief in her ability to overcome barriers was not a significant predictor of mammography screening. An unexpected finding occurred for self-efficacy for communication with providers. Although not statistically significant, women who had low self efficacy for communicating with providers were half as likely to be in compliance with mammography screening guidelines than women who reported a high level of confidence in her ability to communicate with providers. By contrast, women who had low self-efficacy for communicating with providers were more likely to be in compliance with Pap test screening guidelines. Since the data is cross-sectional in nature, one possible explanation of this finding is that the direction of causation is opposite of what would be expected. For example, women who have had Pap tests and who have been exposed to complicated explanations of results or negative experiences communicating with providers may suffer a decreased level of self-efficacy for communication. Those women who had never had a Pap test or who had not had one in several years (noncompliant) may be more optimistic about their ability to communicate effectively with providers. Further exploration of this variable is warranted.

\section{Limitations}

There are several limitations that need to be considered in the interpretation of these results. First, women were not selected at random. This self-selection bias limits the ability to generalize finding to the larger population of low-income foreign-born Hispanic women. 
Another limitation of the study is the reliance on self-reported mammography and Pap test screening data rather than on information from medical records or insurance claims. Research indicates however, that self-reporting data for mammography and Pap test are considered valid for population surveillance among women with diverse sociodemographic characteristics (Zapka et al ., 1996; Champion et al., 1998; Bowman et al., 1997; Sawyer et al., 1989). The homogeneity of the sample with respect to demographic and other characteristics such as education, income, and acculturation made it difficult to observe differences in screening behavior across different levels of these variables. The relatively small sample size may have limited the ability to detect statistically significant differences.

Despite these limitations the present study is unique in that it assessed knowledge, attitudes, beliefs, and correlates these with a breast and cervical cancer screening behavior among a predominantly Central and South
American population for whom information is lacking. Findings indicate that although progress has been made in increasing screening among Hispanic populations, several barriers to appropriate utilization still exist and may be more pronounced among special Hispanic subgroups such as foreign-born Hispanics and recent immigrants. Several other studies have found that factors such as embarrassment, fear of the procedure, fear of results, and lack of knowledge about screening are more frequently reported by Hispanic women, particularly Spanish-speakers, as a reason for not having regular screening exami nations (Morris et al., 1989; Perez-Stable et al., 1994; Harlan et al., 1991). Clearly, population-based breast and cervical cancer screening efforts must continue with a special focus on the specific needs of low-income and foreign born women if we are to reach the Year 2000 breast and cervical cancer screening objectives for Hispanic women (U.S. Department of Health and Human Services, 1991).

\section{References}

ACKERM ANN, S. P.; BRACKBILL, R. M .; BEWERSE, B. A.; CHEAL, N. E. \& SANDERSON, L. M., 1992. Cancer screening behavior among U.S. women: breast cancer, 1987-1989, and cervical cancer, 1988-1989. Morbidity and Mortality Weekly Report, 41(Sup.2):17-34.

ANDERSON, L. M. \& MAY, D. S., 1995. Has the use of cervical, breast, and colorectal cancer screening increased in the United States? American Journal of Public Health, 85:840-842.

BANDURA, A., 1977. Social Learning Theory. Englewood Cliffs: Prentice-Hall.

BASTANI, R.; MAXWELL, A. E.; CARBONARI, J.; ROZELLE, R.; BAXTER, J. \& VERNON, S., 1994. Breast cancer knowledge, attitudes, and behaviors: a comparison of rural health and non-health workers. Cancer Epidemiology, Biomarkers and Prevention, 3:77-84.

BOWM AN, J. A.; SANSON-FISHER, R. \& REDM AN, S., 1997. The accuracy of self-reported pap smear utilisation. Social Science and Medicine, 44:969976.
BREEN, N. \& KESSLER, L., 1994. Changes in the use of screening mammography: evidence from the 1987 and 1990 National Health Interview Surveys. American Journal of Public Health, 84:62-67.

BRISLIN, R. W.; LONNER, W. J. \& THORNDIKE, R. M., 1973. Cross Cultural Research Methods. New York: John Wiley \& Sons.

CALLE, E. E.; FLANDERS, W. D.; THUN, M. J. \& MARTIN, L. M., 1993. Demographic predictors of mammography and Pap smear screening in US women. American Journal of Public Health, 83:53-60.

CHAMPION, V. L.; MENON, U.; MCQUILLEN, D. H. \& SCOTT, C., 1998. Validity of self-reported mammography in low-income African-American women. American Journal of Preventive Medicine, 14:111-117.

CHAPMAN, D. W. \& CARTER, J. F., 1979. Translation procedures for the cross cultural use of measurement instruments. Education Evaluation and Policy Analysis, 1:71-76.

CHAVEZ, L. R.; CORNELIUS, W. A. \& JONES, O. W., 1986. Utilization of health services by Mexican 
immigrant women in San Diego. Women and Health, 11:3-20.

CHAVEZ, L. R.; HUBELL, F. A.; MISHRA, S. I. \& VALDEZ, R. B., 1997. The influence of fatalism on self-reported use of papanicolaou smears. American Journal of Preventive Medicine, 13:418-424.

DALY, M. B.; CLARK, G. M. \& M CGUIRE, W. L., 1985. Breast cancer prognosis in a mixed CaucasianHispanic population. Journal of the National Cancer Institute, 74:753-757.

FERNANDEZ, M. E., 1995. Evaluation of an InteractiveVideodisc on Breast and Cervical Cancer Prevention and Early Detection for Hispanic Women. Master Degree Dissertation, College Park: Faculty of the Graduate School, University of Maryland.

FISHBEI N, M. \& AJZEN, I., 1985. Bel i ef, Attitude, Intention, and Behavior: an Introduction to Theory and Research. Reading: Addison Wesley Publication Company.

FOX, S. A. \& STEIN, J. A., 1991. The effect of physician-patient communication on mammography utilization by different ethnic groups. Medical Care, 29:1065-1081.

FRAZIER, E. L.; JILES, R. B. \& MAYBERRY, R., 1996. Use of screening mammography and clinical breast examinations among black, Hispanic, and white women. Preventive Medicine, 25:118-125.

FREEM AN, H. P. \& WASFIE, T. J., 1989. Cancer of the breast in poor black women. Cancer, 63:25622569.

FRIEDMAN, L. C.; WOODRUFF, A.; LANE, M.; WEINBERG, A. D.; COOPER, H. P. \& WEBB, J. A., 1995. Breast cancer screening behaviors and intentions among asymptomatic women 50 years of age and older. American Journal of Preventive Medicine, 11:218-223.

FULTON, J. P., 1992. Breast cancer screening among low-income Hispanic women in Rhode Island. Rhodelsland Medicine, 75:32-33.

GONZALEZ, J. T. \& GONZALEZ, V. M., 1990. Initial validation of a scale measuring self-efficacy of breast self-examination among low-income Mexican American women. Hispanic Journal of Behavioral Sciences, 12:277-291.

GREEN, L. W. \& KREUTER, M. W., 1991. Health Promotion Planning: An Educational and Environmental Approach. Mountain View: Mayfield Publishing.

HARLAN, L. C.; BERNSTEIN, A. B. \& KESSLER, L. G., 1991. Cervical cancer screening: Who is not screened and why? American Journal of Public Health, 81:885-890.

HEDEGAARD, H. B.; DAVIDSON, A. J. \& WRIGHT, R. A., 1996. Factors associated with screening mammography in low-income women. American Journal of Preventive Medicine, 12:51-56.

HERNANDEZ, M. E., 1992. Focus Group Interview Report: HispanicWomen's Knowledge, Attitudes and Practices Concerning Breast and Cervical Cancer. Denver: AMC Cancer Research Center (mimeo).

HIATT, R. A. \& PASICK, R., 1995. The challenge of interventions in multiethnic communities: breast and cervical cancer screening. American Society of Preventive Oncology, 19th Annual Meeting, Abstracts. Houston: American Society of Preventive Medicine
HURLEY, S. F. \& KALDOR, J. M., 1992. The benefits and risks of mammographic screening for breast cancer. Epidemi ol ogic Reviews, 14:101-130.

KAPLAN, R. M.; NAVARRO, A. M.; CASTRO, F. G.; ELDER, J. P.; MISHRA, S. I.; HUBBELL, A.; CHRVALA, C.; FLORES, E.; RAMIREZ, A.; FERNANDEZ-ESQUER, M. E. \& RUIZ, E., 1996. Increased use of mammography among Hispanic women: baseline results from the $\mathrm{NCl}$ Cooperative Group on Cancer Prevention in Hispanic Communities. American Journal of Preventive Medicine, 12:467471.

KEEFE, S. E., 1980. Acculturation and the extended family among urban M exican Americans. In: Acculturation Theory, Models and Some New Findings (A. M. Padilla, ed.), pp. 85-110, Boulder: Westview Press.

MARIN G.; SABOGAL, F.; MARIN, B. V.; OTERO-SABOGAL, R. \& PEREZ-STABLE, E. J., 1987. Development of a short acculturation scale for Hispanics. Hispanic Journal of Behavioral Science, 9:183205.

MARTIN, L. M.; CALLE, E. E.; WINGO, P. A. \& HEATH, C. W., 1996. Comparison of mammography and Pap test use from the 1987 and 1992 National Health Interview Surveys: Are we closing the gaps? American Journal of Preventive Medicine, 2:82-90.

MILLER, B. A.; KOLONEL, L. N.; BERSTEIN, L.; YOUNG Jr., J. L.; SWANSON, G. M.;WEST, D.; KEY, C. R.; LIFF, J. M.; GLOVER, C. S. \& ALEXANDER, G. A.; COYLE, L.; HANKEY, B. F.; RIES, L. A. G.; KOSARY, C. L.; HARRAS, A.; PERCY, C. \& EDWARDS, B. K., 1996. Racial/Ethnic Patterns of Cancer in the United States,1988-1992. Bethesda: National Cancer Institute/ National Institutes of Health.

MORGAN, C. \& LEVIN, G., 1995. A cancer-prevention intervention for disadvantaged women: design and implementation. Journal of Cancer Education, 10:168-175.

MORRIS, D. L.; LUSERO, G. T.; JOYCE, E. V.; HANNIGAN, E. V. \&TU CKER, E. R., 1989. Cervical cancer, a major killer of Hispanic women: Implications for health education. Health Education, 20:23-28.

MUNN, E., 1993. Nonparticipation in mammography screening: Apathy, anxiety or cost? New Zealand Medical Journal, 106:284-286.

NAPOLES-SPRINGER, A.; PEREZ-STABLE, E. J. \& WASHINGTON, E., 1996. Risk factors for invasive cervical cancer in Latino women. Journal of Medical Systems, 20:277-293.

O'M ALLEY, M. S.; EARP, J. A. L. \& HARRIS, R. P., 1997. Race and mammography use in two North Carolina Counties. American Journal of Public Health, 87:782-786.

PEARLMAN, D. N.; RAKOWSKI, W.; EHRICH, B. \& CLARK, M. A., 1996. Breast cancer screening practices among black, Hispanic, and white women: reassessing differences. American Journal of Pre ventive Medicine, 12:327-337.

PEREZ-STABLE, E. J .; OTERO-SABOGAL, R.; SABOGAL, F.; M CPHEE, S. J \& HIATT, R. A., 1994. Selfreported use of cancer screening tests among Latinos and Anglos in a prepaid health plan. Archives of Internal Medicine, 154:1073-1081. PEREZ-STABLE, E. J.; SABOGAL, F. \& OTERO-SABO- 
GAL, R., 1995. Use of cancer-screening tests in the San Francisco Bay area: comparison of Latinos and Anglos. Journal of the National Cancer Institute. Monographs, 18147-18153.

PEREZ-STABLE, E. J.; SABOGAL, F.; OTERO-SABOGAL, R.; HIATT, R. A. \& MCPHEE, S. J., 1992. Misconceptions about cancer among Latinos and Anglos. Journal of the American Medical Association, 268:3219-3223.

RAMIREZ, A.; MERCADO, S. \& KROMER, M., 1987. Cancer Awareness and Prevention Program in South Texas, Progress Report-Phasel. Tempe: Center for Health Promotion Development and Research, University of Texas.

REYNOLDS, K. D., 1987. A Program to Increasethe Use of Mammography Screening. Doctoral Dissertation, San Antonio: Arizona State University.

RICHARDSON, J. L.; LANGHOLZ, B.; BERNSTEIN, L.; BURCIAGA, C.; DANLEY, K. \& ROSS, R. K., 1992. Stage and delay in breast cancer diagnosis by race, socioeconomic status, age and year. British Journal of Cancer, 65:922-926.

RICHARDSON, J. L.; MARKS, G.; SOLIS, J. M.; COLLINS, L. M.; BIRBA, L. \& HISSERICH, J. C., 1987. Frequency and adequacy of breast cancer screening among el derly Hispanic women. Preventive Medicine, 16:761-774.

RIMER, B. K.; CONAWAY, M. R.; LYNA, P. R.; RAKOWSKI, W.; WOODS-POWELL, C. T.; TESSARO, I.; YARNALL, K. S. \& BARBER, L. T., 1996. Cancer screening practices among women in a community health center population. American Journal of Preventive Medicine, 12:351-357.

RIMER, B.; KEINTZ, M. K.; KESSLER, H. B.; ENDSTROM, P. R. \& ROSAN, J., 1989. Why women resist screening mammography: patient-related barriers. Radiology, 172:243-246.

RIMER, B. K.; TROCK, B.; ENGSTROM, P. F.; LERMAN, C. \& KING, E., 1991. Why do some women get regular mammograms? American Journal of Preventive Medicine, 7: 69-74.

ROETZHEIM, R. G.; VAN DURME, D. J.; BROWNLEE, H. J.; HEROLD, A. H.; WOODARD, L. J. \& BLAIR, C., 1993. Barriers to screening among participants of a media-promoted breast cancer screening project. Cancer Detection and Prevention, 17:367-377.

ROSENSTOCK, I. M. K.; GLANZ, F. M .; LEWIS, C. E. \& RIMER, B. K., 1990. Health Behavi or \& Health Education:Theory Research \& Practice. San Francisco: Jossey-Bass.

SAINT-GERM AIN, M. A. \& LONGMAN, A. J., 1993. Breast cancer screening among older Hispanic women: knowledge, attitudes, and practices. Health Education Quarterly, 20:539-553.

SAWYER, J. A.; EARP, J. A.; FLETCHER, R. H.; DAYE, F. F. \&WYNN, T. M., 1989. Accuracy of women's selfreport of their last Pap smear. American Journal of Public Health, 79:1036-1037.

SCHMITT, N., 1996. Uses and abuses of coefficient alpha. Psychological Assessment, 8:350-353.

SHAPIRO, S.; VENET, L. \& STRAX, P., 1988. Periodic Screening for Breast Cancer. Baltimore: Johns Hopkins Press.

STEIN, J. A.; FOX, S. A.; MURATA, P. J. \& MORISKI, D. E., 1992. Mammography usage and the Health
Belief Model. Health Education Quarterly, 19:447462.

TABAR, L.; FAGERBERG, G.; DUFFY, S. W.; DAY, N. E.; GAD, A. \& GRONTOFT, O. 1992. Update of the swedishtwo-county program of mammographic screening for breast Cancer. Radiologic Clinics of North America, 30:187-210.

TAYLOR, V. M.; S. H. TAPLIN; U RBAN, N.; WHITE, E. \& PEACOCK, S., 1995. Repeat mammography use among women ages 50-75. Cancer Epidemiology, Biomarkers and Prevention, 4:409-413.

TEXAS CANCER COUNCIL, 1994. Breast and Cervical Cancer in Texas: A Guide to Resources and Data. Austin: Texas Cancer Council.

THE NATIONAL CANCER INSTITUTE/CANCER SCREENING CONSORTIUM FOR UNDERSERVED WOMEN, 1995. Breast and cervical cancer screening among underserved women: Baseline survey results from six states. Archives of Family Medicine, 4: 617-624.

TORTOLERO-LUNA, G.; GLOBER, G. A.; VILLARREAL, R.; PALOS, G. \& LINARES, A., 1995. Screening practices and knowledge, attitudes, and beliefs about cancer among Hispanic and non-Hispanic white women 35 years old or older in Nueces County, Texas. Journal of the National Cancer Institute Monographs, 18:49-56.

U.S. BUREAU OF THE CENSUS, 1997. United States Population Estimates, by Age, Sex, Race, and Hispanic Origin, 1990 to 1997. Current Population Survey. Washington D. C. : U. S. Bureau of the Census. (PPL - 91)

U.S. DEPARTMENT OF HEALTH AND HUMAN SERVICES, 1991. Public Health Service: Heal thy People 2000: National Health Promotion and Disease Prevention Objectives. Washington D. C.: U. S. Department of Health and Human Services. (Publ. № (PHS) 91-50212)

VERN ON, S. W.; VOGEL, V. G.; HALABI, S.; GILCHRIST, L. G.; LUNDY, R. O. \& PETERS, G. N., 1992. Breast cancer screening behaviors and attitudes in three racial/ethnic groups. Cancer Supplement, 69:165174.

VOGEL, V. G.; BONDY, M.; HALABI, S.; LORD, J. \& LAVILLE, E. A., 1993. The Texas Breast Screening Project: Part II. Demographics, risk profiles, and health practices of participants. Southern Medical Journal, 86:391-396.

ZAPKA, J. G.; BIGELOW, C.; HURLEY, T.; FORD, L. D.; EGELHOFER, J.; CLOUD, W. M. \& SACHSSE, E., 1996. Mammography use among sociodemographically diverse women: the accuracy of selfreport. American Journal of Public Health, 86: 1016-1021. 